\title{
Comparação entre Métodos para Determinar o Período ANTerior à Interferência de Plantas Daninhas em Feijoeiros Com Distintos Tipos de HÁBitos de CRescimento ${ }^{1}$
}

\author{
Comparison of Methods to Determine the Period Prior to Weed Interference in Bean Plants with \\ Different Types of Growth Habits
}

PARREIRA, M.C. ${ }^{2}$, ALVES, P.L.C.A. ${ }^{3}$, LEMOS, L.B. ${ }^{3}$ e PORTUGAL, J. ${ }^{4}$

\begin{abstract}
RESUMO - A interferência causada pelas plantas daninhas pode reduzir em até $80 \%$ a produtividade de grãos do feijão quando não manejadas de forma correta. Portanto, a decisão sobre o momento de controlá-las é um dos principais aspectos do manejo integrado. Nesse sentido, objetivou-se com este trabalho determinar o período anterior à interferência das plantas daninhas (PAI) em cultivares de feijão com diferentes tipos de hábitos de crescimento. Adotou-se o delineamento experimental de blocos casualizados com quatro repetições. Os tratamentos experimentais foram constituídos de dez períodos de convivência da cultura com as plantas daninhas: 0-7, 0-14, 0-21, 0-28, 0-35, 0-42, 0-49, 0-56, 0-97 (colheita) dias após a emergência (DAE) e mais uma testemunha sem convivio com as plantas daninhas. $\mathrm{O}$ PAI foi determinado por meio de distintas abordagens: o nível arbitrário de $5 \%$ de perda na produtividade, o nível de tolerância (NT) e o de dano no rendimento econômico (PADRE). O PAI obtido foi diferente em todas as abordagens, e os feijoeiros de crescimento indeterminado tipo II apresentaram os menores tempos de convivência.
\end{abstract}

Palavras-chave: Phaseolus vulgaris, cultivares, competição.

ABSTRACT - Beans grain productivity may be reduced by up to $80 \%$ and, therefore, knowing the proper time to control weeds becomes fundamental, his research was conducted in order to determine the period prior to interference (PPI) on bean cultivars of different types' plant growth through distinct approaches: arbitrary level of 5\% productivity loss; tolerance level (TL), and the Weed Period Prior to Economic Loss (WEEPPEL). Experimental treatments were constituted of ten periods of coexistence, periods of the crop with the weeds: $0-7 ; 0-14 ; 0-21 ; 0-28 ; 0-35 ; 0-42 ; 0-49 ; 0-56$; 0 97 (harvesting) days after emergency (DAE), and a control plot, weed free for the entire period. The experimental design was of the Random Block Design, with four replications. PPI was obtained in all of the different approaches, and the bean plant type II with indeterminate growth had the lowest times of coexistence.

Keywords: Phaseolus vulgaris, cultivars, competition.

\section{INTRODUÇÃO}

O feijão comum é um dos alimentos mais tradicionais na alimentação brasileira, com significativa importância social e econômica. O Brasil se destaca como maior produtor e consumidor mundial de feijão-carioca (Tavares et al., 2013). Nesta cultura, o controle de plantas daninhas é, em média, de 20 a $30 \%$ do seu custo total de produção (Gerlach et al., 2013). Por esse motivo, o conhecimento da comunidade infestante do local é essencial na tentativa de se reduzir o uso de herbicidas e, consequentemente, o impacto negativo causado pela má utilização desses produtos.

\footnotetext{
Recebido para publicação em 23.1.214 e aprovado em 22.7.2014.

2 Universidade Federal do Pará, Cametá-PA, Brasil, <mcparreira@ufpa.br>; ${ }^{3}$ Universidade Estadual Paulista Jaboticabal-SP, Brasil; ${ }^{4}$ Instituto Politécnico de Beja (IPBeja), Beja, Portugal.
} 
A competição das plantas daninhas com o feijoeiro constitui um dos principais fatores da baixa produtividade que a cultura apresenta (Ferreira et al., 2006). Os feijoeiros têm limitada capacidade competitiva com as plantas daninhas, e o grau de interferência depende da interação entre a comunidade infestante e a cultura, dos fatores ambientais e do periodo de convivência (Caton et al., 2001.).

No que diz respeito à capacidade competitiva das plantas de feijão, pode-se dizer que a morfologia da planta é fator preponderante, em que os genótipos de hábitos de crescimento dos tipos I e II, com porte ereto e pouco ramificados, são menos competitivos. Por outro lado, os genótipos tipo III, os mais cultivados, promovem maior cobertura do solo, por serem ramificados e prostrados (Santos \& Gavilanes, 2006).

Existem várias abordagens para avaliar o período anterior à interferência das plantas daninhas às culturas; contudo, na maioria das publicações relacionadas a esse tema, o nivel arbitrário de $5 \%$ de perdas aceitáveis na produtividade é o mais utilizado. Na cultura do feijão não é diferente: na quase sua totalidade, no período entre 2012 e 2013 foi utilizado o nível arbitrário de $5 \%$ de redução na produtividade (Ghamari \& Ahmadvand, 2012; Parreira et al., 2012, 2013; Bressanin et al., 2013; Frenda et al., 2013). No Brasil, a análise econômica tem pouca demanda, mas gera muito interesse na atual conjuntura econômica.

No entanto, existem outros parâmetros, como o nível de tolerância, que é um conceito aplicável na entomologia em nível econômico de ataque, no sentido em que se tolera a presença de inimigos das culturas (Amaro \& Baggiolini, 1982). Em plantas daninhas, o nível de tolerância (NT) é utilizado até um nível economicamente viável, sendo uma relação de custo-beneficio, na qual os gastos no controle das plantas daninhas têm de ser menores que os prejuízos causados por elas (Portugal, 2010). Esse conceito traduz quando é vantajoso economicamente combater as plantas daninhas que estão na cultura de interesse, ou seja, o quão é aceitável a redução econômica da produtividade.

Em 2005, Vidal e colaboradores afirmaram que aspectos econômicos, como controle de custos e valor monetário da safra, devem ser utilizados como critério para determinar o período de interferência das plantas daninhas aceitável antes de se decidir como controlálas, estabelecendo o período anterior de dano ao rendimento econômico (PADRE). O PADRE representa os dias a partir da germinação ou emergência em que a cultura pode conviver com a comunidade infestante sem que ocorram prejuízos econômicos.

A hipótese deste trabalho é de que o PAI calculado por vias econômicas seria mais vantajoso para o produtor do que estipular arbitrariamente um nível aceitável de perdas na produtividade para determinar esse período. Assim, o objetivo desta pesquisa foi determinar o período anterior à interferência (PAI) em feijoeiros de tipos de hábitos de crescimento indeterminados, usando-se diferentes abordagens: nivel de $5 \%$ de perda aceitável na produtividade, nivel de tolerância (NT) e com o período anterior ao dano no rendimento econômico (PADRE).

\section{MATERIAL E MÉTODOS}

Três experimentos foram realizados em campo, no Estado de São Paulo, que se encontra em latitude de $21^{\circ} 15^{\prime} 22^{\prime \prime}$, longitude de $48^{\circ} 18^{\prime} 58^{\prime \prime}$ e altitude de $595 \mathrm{~m}$. Em cada experimento foram utilizados três cultivares de feijão, do grupo carioca: Pérola, BRS Pontal e IPR Juriti Claro. As descrições desses cultivares são:

a) Pérola - possui hábito de crescimento indeterminado tipo II/III, porte semiereto, resistente ao mosaico comum, ferrugem e mancha angular (Embrapa, 2013).

b) BRS Pontal - é um cultivar de alto potencial produtivo, com hábito de crescimento indeterminado tipo III e arquitetura de planta prostrada. Apresenta resistência ao mosaico comum e antracnose; resistência intermediária a crestamento bacteriano, fusarium e ferrugem (Embrapa, 2013).

c) IPR 139 (Juriti Claro) - possui hábito de crescimento indeterminado tipo II, porte ereto, adaptação a colheita mecânica, alto potencial produtivo, moderadamente tolerante ao crestamento bacteriano comum, suscetível à antracnose e resistente a mosaico comum, oídio e ferrugem (Moda-Cirino et al., 2003). 
O solo da área experimental foi classificado como Latossolo Vermelho-Escuro, de textura argilosa, cujo resultado da análise química encontra-se na Tabela 1. O preparo do solo foi efetuado no sistema convencional, utilizando $360 \mathrm{~kg} \mathrm{ha}^{-1}$ do adubo químico 05-25-20 na semeadura; também foi feita adubação de $\mathrm{N}$ em cobertura na dose de $40 \mathrm{~kg} \mathrm{ha}^{-1}$, tendo ureia como fonte.

A semeadura foi executada por meio da semeadora de plantio convencional de cinco linhas, com o espaçamento de 0,45 $\mathrm{m}$ entre elas, em uma densidade de 17 sementes por metro, realizada no dia 8 de maio de 2012 , sendo classificado como plantio de inverno; utilizou-se, quando da ausência de chuvas, sistema de irrigação suplementar por aspersão convencional. No decorrer do período experimental, foram feitas aplicações preventivas de inseticidas e fungicidas em área total, visando à sanidade da cultura.

As parcelas experimentais foram constituídas de cinco linhas de semeadura por cinco metros de comprimento, resultando em área de $11,25 \mathrm{~m}^{2}$. As duas linhas externas de cada parcela experimental foram descartadas, sendo elas as bordaduras; efetivamente, a área útil constituiu-se das três linhas centrais de cada parcela, resultando em $6,75 \mathrm{~m}^{2}$ amostrais.
Os tratamentos experimentais foram constituídos de dez períodos de convivência da cultura com as plantas daninhas: 0-7, 0-14, $0-21,0-28,0-35,0-42,0-49,0-56,0-97$ (colheita) dias após a emergência (DAE) e mais uma testemunha sem convivio com as plantas daninhas. Esses períodos de convivência foram estudados para os três cultivares utilizados. Para cada cultivar, foi utilizado o delineamento experimental em blocos casualizados com quatro repetições.

Os dados de precipitação pluvial, umidade relativa do ar e temperaturas mínima, máxima e média no decorrer do período experimental estão apresentados na Tabela 2.

A avaliação da comunidade infestante foi feita ao término de cada período de convivência de cada parcela. As plantas daninhas presentes em duas áreas amostrais, de $0,25 \mathrm{~m}^{2}$, tomadas aleatoriamente nas parcelas experimentais foram removidas, identificadas, separadas por espécie, contadas e secas em estufa com circulação forçada de ar a $70{ }^{\circ} \mathrm{C}$ por 96 horas, para determinação da massa seca, realizada com o auxílio de balança com precisão de $0,01 \mathrm{~g}$. As parcelas experimentais, após o término de seus respectivos períodos de convivência, foram então mantidas sem plantas daninhas até a colheita, por meio de capinas periódicas.

Tabela 1 - Análise química do solo da área experimental. Jaboticabal-SP

\begin{tabular}{|c|c|c|c|c|c|c|c|c|c|}
\hline \multicolumn{10}{|c|}{ Análise química } \\
\hline \multirow{2}{*}{$\begin{array}{c}\mathrm{pH} \\
\left(\mathrm{CaCl}_{2}\right)\end{array}$} & \multirow{2}{*}{$\begin{array}{c}\mathrm{MO} \\
\left(\mathrm{g} \mathrm{dm}^{-3}\right)\end{array}$} & \multirow{2}{*}{$\begin{array}{l}\text { P Resina } \\
\left(\mathrm{mg} \mathrm{dm}^{-3}\right)\end{array}$} & K & $\mathrm{Ca}$ & $\mathrm{Mg}$ & $\mathrm{H}+\mathrm{Al}$ & $\mathrm{SB}$ & $\mathrm{T}$ & \multirow{2}{*}{$\frac{\mathrm{V}}{(\%)}$} \\
\hline & & & \multicolumn{6}{|c|}{$\left(\mathrm{mmol}_{\mathrm{c}} \mathrm{dm}^{-3}\right)$} & \\
\hline 5,6 & 17 & 16 & 1,9 & 29 & 20 & 22 & 50,9 & 72,9 & 70 \\
\hline
\end{tabular}

Fonte: Laboratórios de Física do Solo e de Fertilidade do Solo da FCAV/UNESP.

Tabela 2 - Dados médios de temperaturas (mínima, máxima e média), umidade relativa do ar e precipitação durante o período experimental, no ano de 2012

\begin{tabular}{|c|c|c|c|c|c|}
\hline \multirow{2}{*}{ Mês } & \multicolumn{3}{|c|}{ Temperatura $\left({ }^{\circ} \mathrm{C}\right)$} & UR & Precipitação pluvial \\
\cline { 2 - 6 } & Máxima & Mínima & Média & $(\%)$ & $(\mathrm{mm})$ \\
\hline Maio & 26,2 & 14,4 & 19,4 & 76,0 & 73,0 \\
\hline Junho & 26,0 & 15,0 & 19,4 & 80,7 & 139,2 \\
\hline Julho & 27,3 & 12,7 & 19,0 & 66,3 & 13,7 \\
\hline Agosto & 29,0 & 13,7 & 20,5 & 57,1 & 0 \\
\hline
\end{tabular}

Fonte: Estaçao Agroclimatológica FCAV-UNESP. 
Com os dados da comunidade infestante foi calculada a importância relativa da comunidade infestante, que consiste de um indice que envolve três fatores: frequência relativa, densidade relativa e dominância relativa, seguindo fórmulas propostas por MuellerDombois \& Ellemberg (1974).

A colheita foi feita manualmente aos 97 DAE, coletando-se as plantas localizadas nas três linhas centrais de cada parcela, quando a umidade dos grãos aproximou-se de $13 \%$. As vagens foram trilhadas mecanicamente, e os grãos colhidos foram pesados em balança de precisão de 0,01 g.

A análise dos dados de produtividade foi realizada individualmente para cada cultivar, e os resultados foram submetidos à análise de regressão pelo modelo sigmoidal de Boltzmann.

$$
y=\frac{(P 1-P 2)}{1+e^{\left(X-X_{0}\right) / d x}}+P 2
$$

em que: $y=$ produtividade de grãos do feijoeiro em função dos periodos de convivência; $P 1=$ produção máxima obtida nas plantas mantidas capinadas durante todo o ciclo; $P 2=$ produção mínima obtida nas plantas em convivência com as plantas daninhas durante o período máximo (97 dias); $(P 1-P 2)=$ perdas de produção; $X=$ limite superior do período de convivência; $X_{0}=$ limite superior do período de convivência, que corresponde ao valor intermediário entre a produção máxima e a mínima; e $d x=$ parâmetro que indica a velocidade de perda de produção em função do tempo de convivência.

Com base nas equações de regressão, foram determinados os períodos anteriores à interferência das plantas daninhas para o nível arbitrário de tolerância de 5\% de redução na produtividade do feijoeiro, em relação ao tratamento mantido na ausência das plantas daninhas. Na realização das análises de regressão foi utilizado o programa Origin $\mathbb{}\left({ }^{\circ}\right.$

A análise do nivel de tolerância (NT) foi feita de acordo com Portugal (2010):

$$
Y^{*}=\frac{C}{P . Y_{p p} . E} \times 100
$$

em que: $Y^{*}=$ porcentagem de perdas; $C=$ preço do controle das plantas daninhas: valor do herbicida mais sua aplicação (custos fixos, como depreciação do trator e pulverizador, e custos variáveis, como mão de obra, lubrificante e combustivel); $P=$ preço por quilo do feijão pago ao produtor; $Y_{p p}=$ produção potencial paga ao produtor; e $E$ = fator de segurança do herbicida.

Para determinação do PADRE, foi seguida a proposta de Vidal et al. (2005), sendo a fórmula:

$$
\mathrm{DM}=\mathrm{PADRE}=(\mathrm{PH}+\mathrm{CA}) /(\mathrm{PP} * \mathrm{RC})
$$

$\mathrm{O}$ preço do herbicida $(\mathrm{PH})$ por área é somado ao custo de aplicação (CA). A perda de rendimento é dada pela perda percentual diária (PP), multiplicada pelo rendimento da cultura (RC), multiplicados pelo número de dias de convivência das plantas daninhas após a emergência da cultura (DM). A perda percentual diária é estabelecida na regressão linear, na divisão de $\mathrm{b}$ (coeficiente de declividade) por a (interceptação no eixo y).

Na parametrização do modelo, foram utilizados valores de mercado da data da colheita (2012). O controle de plantas daninhas em pósemergência por hectare $(\mathrm{C})$ resultou em custo de $R \$ 125,80$ (fluazifop-p-butyl + fomesafen) para o controle de folhas largas e de algumas espécies de folhas estreitas, mais $R \$ 35,00$ (cletodim) para o manejo de gramíneas de difícil controle $(\mathrm{PH})$. Além do preço do herbicida, foi adicionado o custo de aplicação do herbicida por hectare (custos fixos e variáveis). A faixa de variação pode ser grande, porém utilizou-se o valor médio de $\mathrm{R} \$ 10,83$ (CA) por hectare aspergido (Richetti \& Mello, 2013). Portanto, o controle das infestantes por hectare foi fixado em $\mathrm{R} \$ 171,63$, o que equivale a US\$ 80.00 ha $^{-1}$, considerando o câmbio de 03/09/2012.

A produtividade da cultura (produção potencial) foi obtida em cada caso particular a partir da testemunha, livre da convivência com as plantas daninhas durante todo o período experimental. O valor monetário do grão de feijão foi obtido por consulta à Conab (2012), sendo fixado em R\$2,00 kg-1 (US\$ $0,92 \mathrm{~kg}^{-1}$ ) na região em que o experimento foi realizado (São Paulo). O fator de segurança do herbicida varia de 0 a 1 , sendo utilizado o nível arbitrário de 0,8 nesse caso. 


\section{RESULTADOS E DISCUSSÃO}

\section{Comunidade infestante}

A comunidade infestante foi semelhante nos três experimentos, composta por 20 espécies de plantas daninhas, sendo $70 \%$ de eudicotiledôneas e 30\% de monocotiledôneas. Entre as eudicotiledôneas, destacaram-se as famílias Asteraceae, com quatro espécies, e Amaranthaceae, com duas. Também estavam presentes as famílias Brassicaceae, Chenopodiaceae, Convulvulaceae, Euphorbiaceae, Malvaceae, Portulacaceae, Rubiaceae e Solanaceae, com uma espécie cada. Das monocotiledôneas, uma espécie pertencia à família Cyperaceae, outra à Commelinaceae e quatro à família Poaceae (Tabela 3) . Scholtenet al. (2011) e Parreira et al. (2012, 2013) também encontraram essas mesmas famílias de plantas daninhas em experimentos realizados com o feijoeiro em condições de inverno, em Jaboticabal, SP.

Segundo Deuber (1992) e Ferreira et al. (1994), as espécies de plantas daninhas anuais que predominam no inverno são eudicotiledôneas, ocorrendo poucas espécies monocotiledôneas nos períodos mais frios. As espécies de gramíneas perenes são exceções, sobrevivendo no período frio, com redução do seu crescimento ou entrando em repouso vegetativo.

Para os três cultivares analisados, a importância relativa (IR) de Raphanus raphanistrum apresentou comportamento hiperbólico, em que no início do período experimental o índice foi alto, ultrapassando $78 \%$ em média (aos $7 \mathrm{DAE}$ ). Isso se deve, nesse primeiro momento, principalmente ao elevado número de indivíduos encontrados na área, que foi de 129, 43 e 66 plantas $\mathrm{m}^{-2}$, para Pérola, BRS Pontal e IPR Juriti, respectivamente (Figura 2). Contudo, a massa seca específica dessa planta daninha foi de valor quase irrelevante: de 0,65, 3,35 e $1 \mathrm{~g} \mathrm{~m}^{-2}$, respectivamente para os três cultivares (Figura 3 ). No decorrer dos experimentos, o IR foi reduzindo gradativamente, chegando à média de $30 \%$ aos 28 DAE. A partir dessa época, foi aumentando o IR da espécie, superando a média de $90 \%$ na colheita, notadamente devido a sua extensa produção de biomassa, pois 21,30 e 30 indivíduos acumularam 865, 741 e 885 gramas $\mathrm{m}^{-2}$ de massa seca, para os cultivares Pérola, BRS Pontal e IPR Juriti, respectivamente (Figuras 2 e 3 ). Esses valores de massa seca foram determinantes para a redução da produtividade da cultura. Essa espécie é de grande capacidade

Tabela 3 - Plantas daninhas componentes da comunidade infestante da área experimental

\begin{tabular}{|c|c|c|c|}
\hline Família & Nome científico & Nome popular & \\
\hline \multirow{2}{*}{ Amaranthaceae } & Alternanthera ficoidea (L.) SM & Apaga-fogo & \multirow{2}{*}{ Eudicotiledônea } \\
\hline & Amaranthus deflexus L. & Caruru & \\
\hline \multirow{4}{*}{ Asteraceae } & Acanthospermum hispidum DC & Carrapicho-de-carneiro & \multirow{4}{*}{ Eudicotiledônea } \\
\hline & Bidens pilosa $\mathrm{L}$. & Picão-preto & \\
\hline & Xanthium strumarium L. & Carrapichao & \\
\hline & Ageratum conyzoides L. & Mentrasto & \\
\hline Brassicaceae & Raphanus raphanistrumL. & Nabiça & Eudicotiledônea \\
\hline Chenopodiaceae & Chenopodium ambrosioides L. & Mastruz & Eudicotiledônea \\
\hline Convolvulaceae & Ipomoea grandifolia (Dammer) O'Donell & Corda-de-viola & Eudicotiledônea \\
\hline Commelinaceae & Commelina benghalensis L. & Trapoeraba & Monocotiledônea \\
\hline Cyperaceae & Cyperus rotundus L. & Tiririca & Monocotiledônea \\
\hline Euphorbiaceae & Euphorbia heterophylla L. & Leiteiro & Eudicotiledônea \\
\hline Malvaceae & Sida rhombifolia L. & Guanxuma & Eudicotiledônea \\
\hline \multirow{4}{*}{ Poaceae } & Cenchrus echinatus L. & Capim-carrapicho & \multirow{4}{*}{ Monocotiledônea } \\
\hline & Digitaria sp. & Capim-colchão & \\
\hline & Eleusine indica (L.) Gaertn & Capim-pé-de-galinha & \\
\hline & Panicum maximum Jacq. & Capim-colonião & \\
\hline Portulacaceae & Portulaca oleracea L. & Beldroega & Eudicotiledônea \\
\hline Rubiaceae & Richardia brasiliensis Gomes & Poaia-branca & Eudicotiledônea \\
\hline Solanaceae & Nicandra physalodes (L.) Pers. & Nicandra & Eudicotiledônea \\
\hline
\end{tabular}


de competição, tendendo a infestar de modo intenso as culturas, especialmente as de inverno (Kissmann \& Groth, 1999). Parreira et al. (2012, 2013) e Scholten et al. (2011) verificaram que, em feijão de inverno, $R$. raphanistrum atingiu valores de densidade e massa seca elevados, reduzindo em média $63,2 \%$ a produtividade da cultura.

A espécie Digitaria sp. comportou-se de modo semelhante nos três cultivares (Figura 1). Foram encontrados altos índices de IR dessa espécie, primordialmente por ter grande número de indivíduos, atingindo até

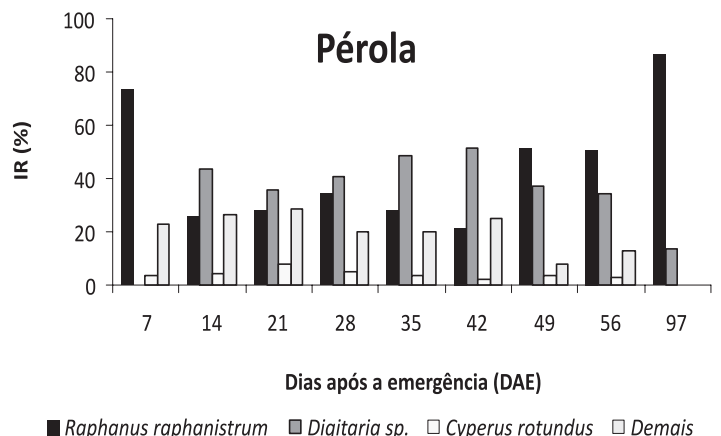

BRS Pontal

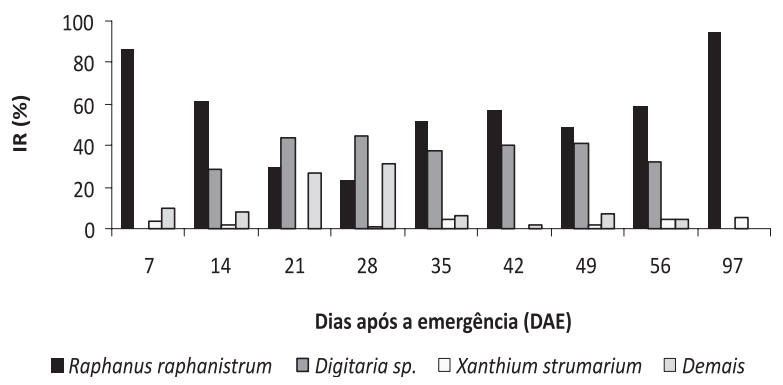

IPR Juriti

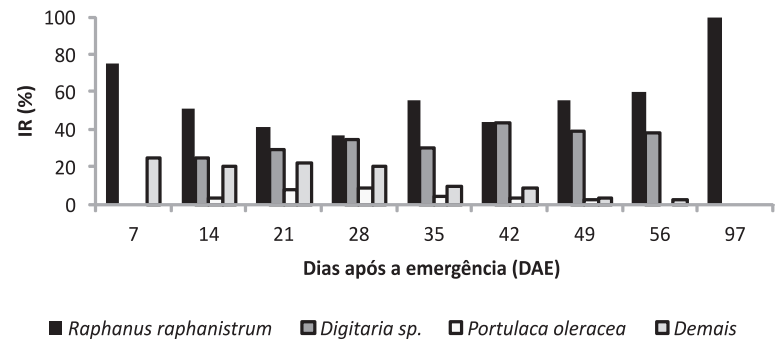

Figura 1 - Importância relativa (\%) das principais plantas daninhas, $R$. raphanistrum, Digitaria sp., C. rotundus, $X$. strumarium e P. oleraceae, e das demais plantas que compuseram a comunidade infestante ao final dos períodos de convivência, para os cultivares de feijão Pérola, BRS Pontal e IPR Juriti.
425 plantas $\mathrm{m}^{-2}$ no cultivar Pontal aos 28 DAE (Figura 2), e nos cultivares Pérola e IPR Juriti ela apresentou 395 e 297 plantas $\mathrm{m}^{-2}$, aos 42 e $28 \mathrm{DAE}$, respectivamente, o que evidencia o alto poder de infestação dessa espécie.

A partir dos 14 DAE, Digitaria sp. foi observada na área, mas por ocasião da colheita sua IR foi reduzida por $R$. raphanistrum, chegando a menos de $15 \%$ ou a zero, não sendo encontrados indivíduos desta espécie (Figuras 1 e 2). Para o cultivar Pérola, o IR oscilou de 34 a 51\%; para BRS Pontal, de 28 a 44\%; e para IPR Juriti a variação foi de 24 a $43 \%$. De modo geral, o gênero Digitaria está presente em praticamente todas as áreas de produção agrícola, normalmente referenciada como as espécies $D$. horizontalis, D. nuda, D. ciliaris e $D$. sanguinalis. Contudo, apenas no Estado de São Paulo já foram relatadas 14 espécies diferentes de capim-colchão (Canto-Dorow, 2001); no Estado de Rondônia, Borchartt al. (2011), em estudo semelhante, também encontraram este gênero com mais de $75 \%$ de IR em feijoeiro semeado em plantio direto.

A terceira espécie com maior IR se diferenciou nos três cultivares, sendo Cyperus rotundus, Xantium strumarium e Portulacacea oleraceae para os cultivares Pérola, BRS Pontal e IPR Juriti, respectivamente, mas nenhuma destas três espécies atingiram 10\% de IR (Figura 1).

A espécie C. rotundus estava presente em alta densidade no cultivar Pérola, sendo encontrada em todo o período experimental, exceto na colheita, quando só foi encontrada $R$. raphanistrum. A densidade de C. rotundus variou de 1 a 16 plantas $\mathrm{m}^{-2}$. Para o cultivar BRS Pontal, $X$. strumarium foi encontrada em quase todo o período experimental, porém em menor densidade. $P$. oleraceae estava presente dos 14 aos 49 DAE no cultivar Juriti, variando de 1 a 51 plantas $\mathrm{m}^{-2}$ (Figura 2).

\section{Produtividade da cultura}

Houve redução de $68,4,76,8$ e $69,1 \%$ da produtividade do feijoeiro em decorrência da convivência com as plantas daninhas durante todo o ciclo para os cultivares Pérola, BRS Pontal e IPR Juriti, respectivamente (Tabela 4). Em trabalhos recentes, nas mesmas condições de cultivo e época de semeadura, utilizando 

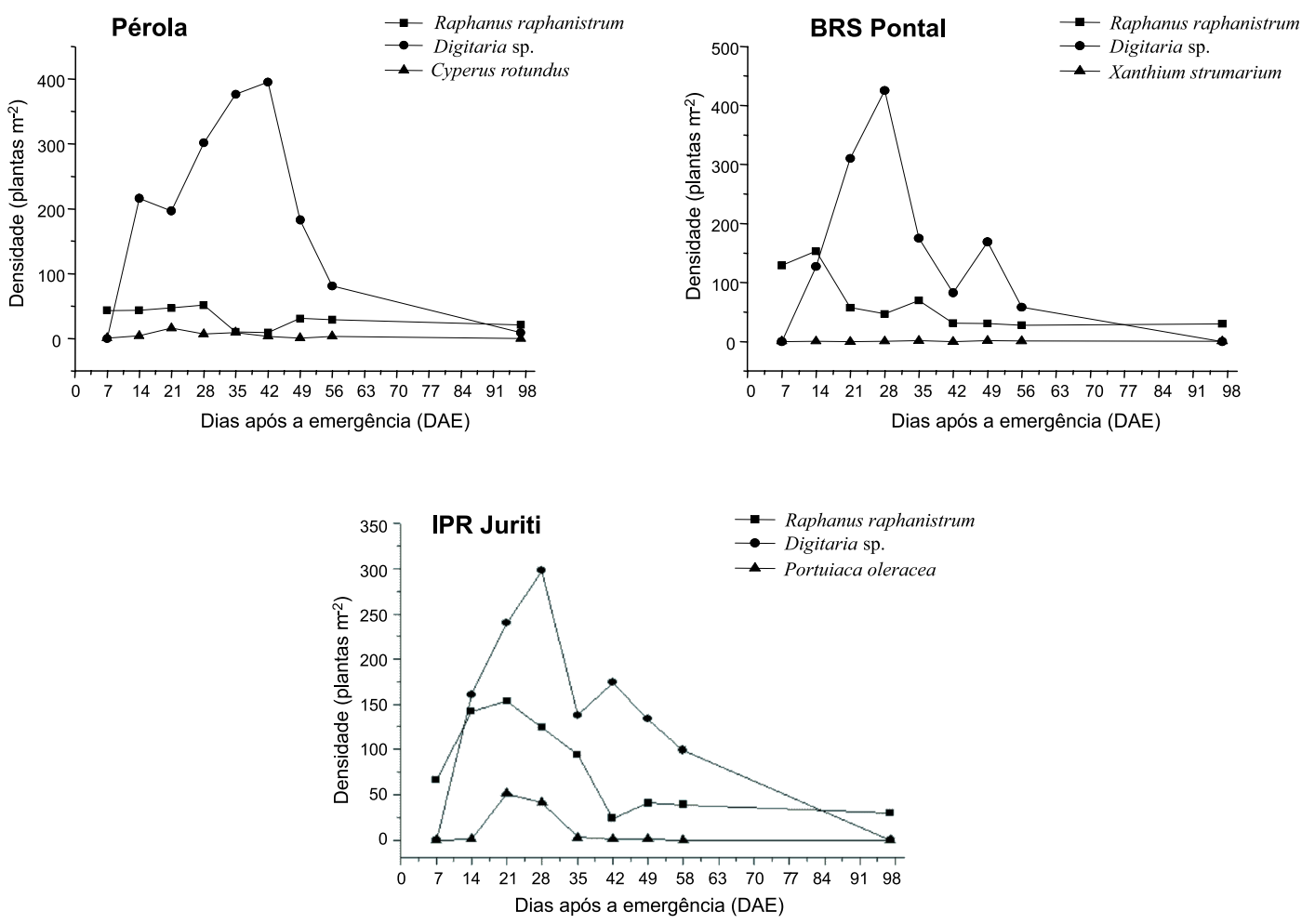

Figura 2 - Densidade das principais plantas daninhas infestantes (plantas $\mathrm{m}^{-2}$ ) ao final dos períodos de convivência, para os cultivares de feijao Pérola, BRS Pontal e IPR Juriti.
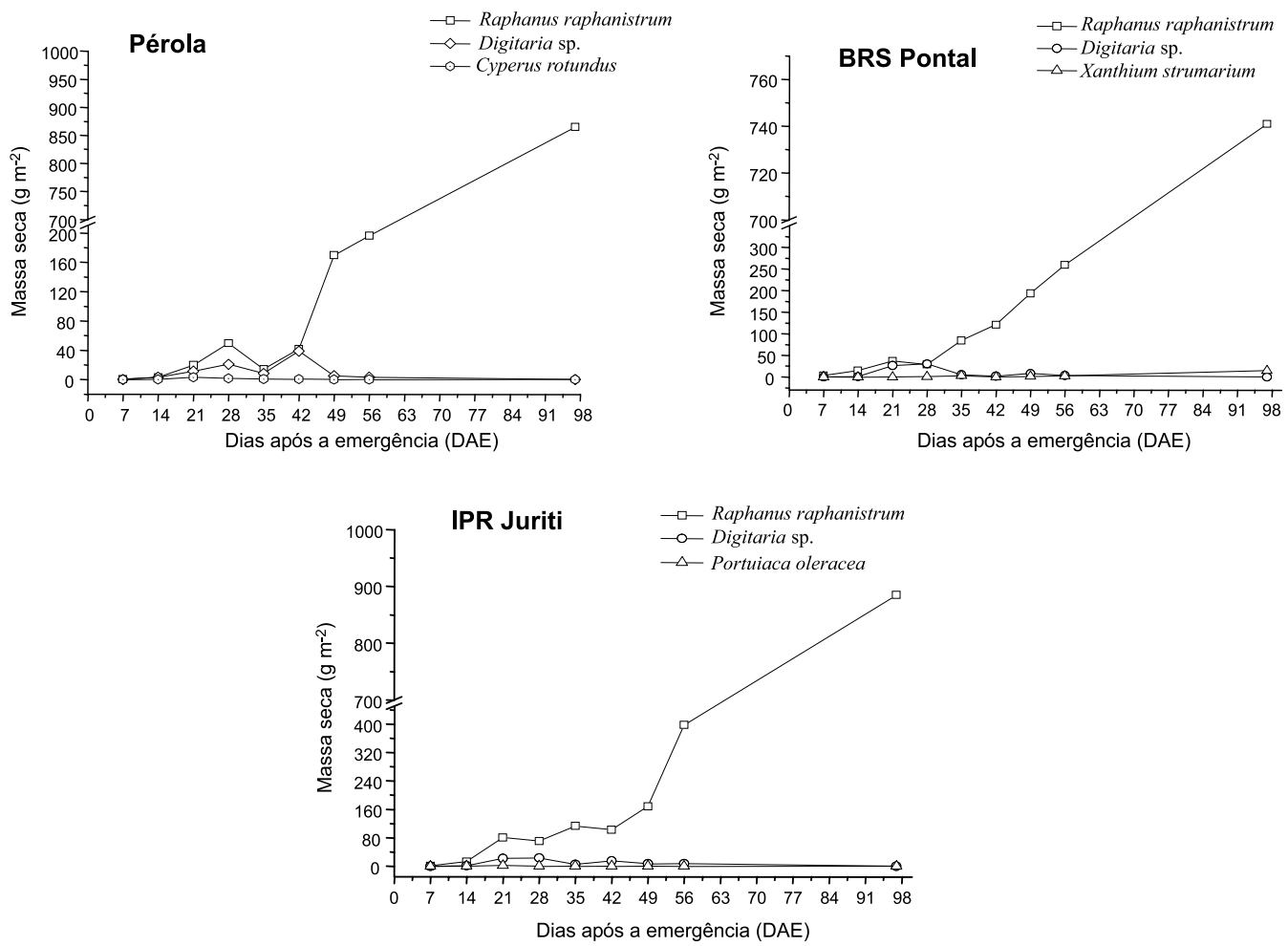

Figura 3 - Massa seca das principais plantas daninhas infestantes $\left(\mathrm{g} \mathrm{m}^{-2}\right)$ ao final dos períodos de convivência, para os cultivares de feijao Pérola, BRS Pontal e IPR Juriti. 
Tabela 4 - Parâmetros determinados para as equações sigmoidais de Boltzmann ajustadas aos dados de produtividade de grãos em função dos períodos de convivência com as plantas daninhas, para os cultivares Pérola, BRS Pontal e IPR Juriti

\begin{tabular}{|c|c|c|c|}
\hline \multirow{2}{*}{ Parâmetro } & \multicolumn{3}{|c|}{ Cultivares } \\
\cline { 2 - 4 } & Pérola & BRS Pontal & IPR Juriti \\
\hline P1 & 2.975 & 3.326 & 3.335 \\
\hline P2 & 941 & 796 & 3.028 \\
\hline X0 & 42,2 & 38,3 & 34,6 \\
\hline $\mathrm{R}^{2}$ & 7,6 & 6,7 & 0,9 \\
\hline Redução da produção & 0,97 & 0,97 & $69,1 \%$ \\
\hline
\end{tabular}

Obs.: y (produtividade de grãos do feijoeiro em função dos períodos de convivência), P1 (produção máxima obtida nas plantas mantidas capinadas durante todo o ciclo), P2 (produção mínima obtida nas plantas em convivência com as plantas daninhas durante o período máximo de 97 dias), X (limite superior do período de convivência), X0 (limite superior do período de convivência, que corresponde ao valor intermediário entre a produção máxima e mínima), dx (parâmetro que indica a velocidade de perda de produção em função do tempo de convivência) e $\mathrm{R}^{2}$ (coeficiente de regressão).

cultivares de feijão-carioca de hábito de crescimento indeterminado tipo III, as perdas de produtividade foram de 60\% (Parreira et al., 2012) e 63\% (Scholten et al., 2011)

Todavia, em estudos na região amazônica, nos cultivares EV x 91-2E-2, BR8 Caldeirão e BR IPEAN V69 de feijão-frade, de hábito de crescimento indeterminado tipo IV, as perdas foram acima de 60, 70 e 90\%, respectivamente (Oliveira et al., 2009). Na região Nordeste brasileira o cultivar BR 16, também de feijãofrade, teve redução de $90 \%$ em seu rendimento de grãos (Freitas et al., 2009). Esses resultados evidenciam que o grau de interferência depende das manifestações de fatores ligados à comunidade infestante (composição específica, densidade e distribuição), à própria cultura (espécie, espaçamento, variedade e densidade de plantio) e à época e extensão do período de convivência. Além disso, ele pode ser alterado pelas condições edáficas, climáticas e de tratos culturais (Pitelli, 1985).

O feijoeiro apresenta baixa capacidade competitiva e está enquadrado no grupo de culturas agrícolas que menos sombreiam o solo, o que leva a cultura à intensa interferência de plantas daninhas (Casper \& Jackson, 1997). Ademais, é possivel inferir que as plantas cultivadas têm menor capacidade competitiva, em razão do processo de melhoramento pelo qual passaram, do que espécies da comunidade infestante (plantas não cultivadas); como consequência, apresentam menor tolerância aos efeitos da competição (Fontes et al., 2003).

De acordo com a equaçao de Boltzmann, a maior produção na ausência de plantas daninhas foi obtida pelo cultivar IPR Juriti, superando $3.330 \mathrm{~kg} \mathrm{ha}^{-1}$, que possui hábito de crescimento indeterminado (tipo II), seguido pelo cultivar BRS Pontal, de hábito de crescimento indeterminado (tipo III), com $3.326 \mathrm{~kg} \mathrm{ha}^{-1}$, e pelo cultivar Pérola, de hábito de crescimento indeterminado (tipo II/III), com menor produção, atingindo $2.975 \mathrm{~kg} \mathrm{ha}^{-1}$ (Tabela 4).

O cultivar que apresentou maior produtividade na presença de plantas daninhas foi IPR Juriti (1.028 $\left.\mathrm{kg} \mathrm{ha}^{-1}\right)$, apesar de possuir arquitetura de planta mais ereta, o que proporciona melhores condições para a ocorrência de plantas daninhas fotoblásticas positivas e daquelas de ciclo fotossintético $\mathrm{C}_{4}$. O cultivar BRS Pontal apresentou a menor produção na presença de plantas daninhas (796 kg ha-1) e também obteve a menor velocidade de redução de produtividade entre as três $(\mathrm{dx}=6,7)$.

\section{Periodos de interferência}

Para BRS Pontal, que possui crescimento indeterminado tipo III, muito prostrado, sombreando consequentemente as entrelinhas com rapidez, o PAI foi de 20 dias após a emergência (DAE) (Figura 4). O cultivar Pérola possui caracteristicas dos dois tipos de 

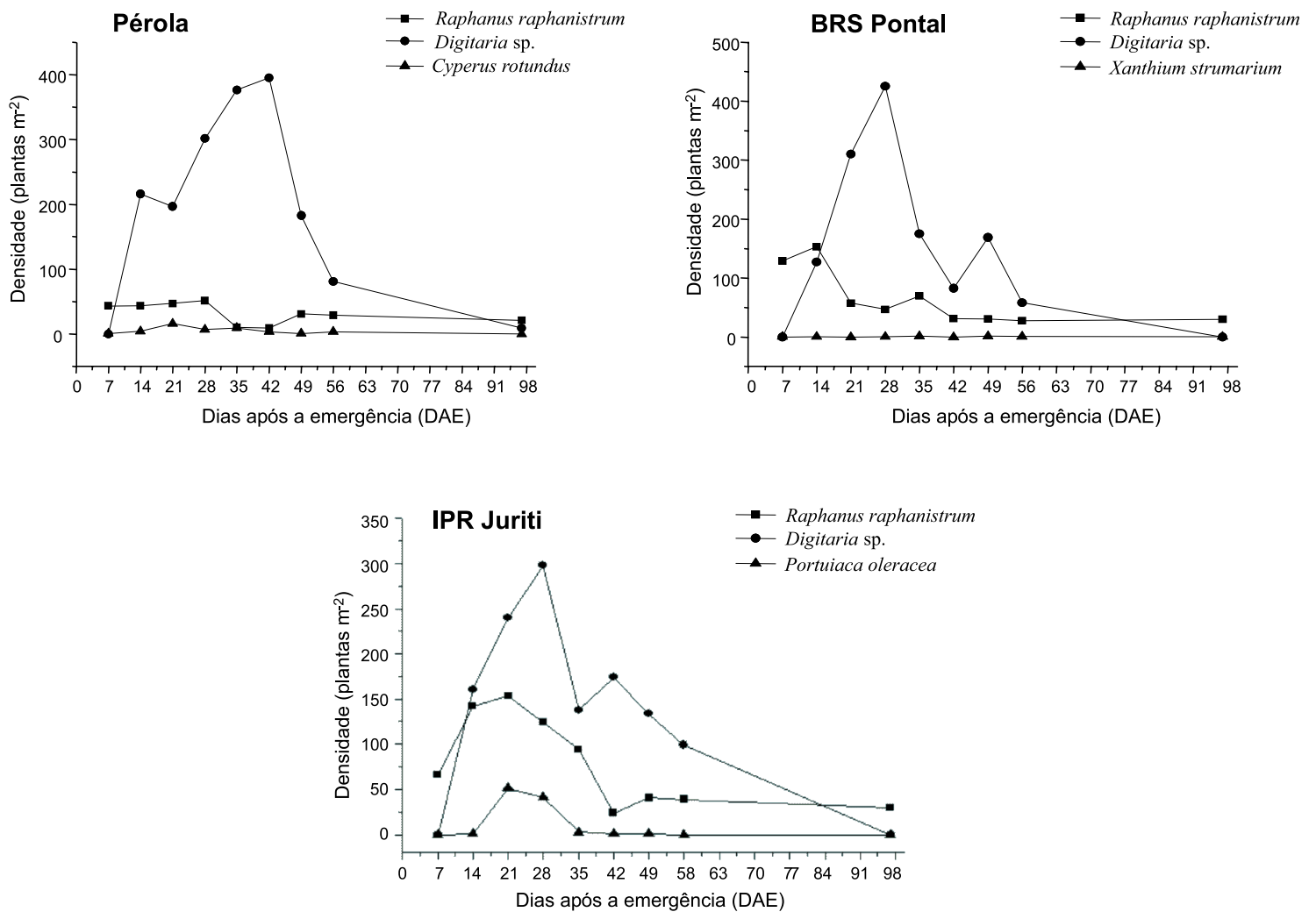

Figura 4 - Produtividade de grãos dos feijoeiros Pérola, BRS Pontal e IPR Juriti, em resposta aos períodos de convivência com as plantas daninhas, com a representação dos períodos anteriores de interferência, considerando a perda arbitrária de 5\% na produtividade e o nível de tolerância (NT).

crescimento (crescimento indeterminado II/III), e o ambiente determinará qual irá prevalecer. Nas condições deste trabalho, prevaleceram as características do tipo III, assemelhando-se a BRS Pontal, resultando em um PAI de 22 DAE. Por outro lado, o cultivar IPR Juriti possui crescimento indeterminado tipo II, de arquitetura mais ereta e, consequentemente, foi mais sensivel à interferência da comunidade infestante, resultando em PAI de 7 DAE.

Parreira et al. (2013), utilizando o mesmo cultivar Pérola, na mesma região e época de cultivo, obtiveram PAI mais extenso, que variou de 29 a 38 DAE na ausência e na presença de resíduos vegetais de crotalária. Entretanto, Scholten et al. (2011) e Bressanin et al. (2013), utilizando feijoeiros com crescimento indeterminado tipo III (cv. Rubi), na região de Jaboticabal, obtiveram resultados semelhantes aos do cultivar BRS Pontal, com PAI variando de 19 a 23 DAE.
Utilizando o nível de tolerância (NT), de acordo com cada caso, foi verificada perda aceitável economicamente na produção de 3,6, 3,2 e 3,2\% para Pérola, BRS Pontal e IPR Juriti, respectivamente (Figura 4.). Essa oscilação entre os diferentes tipos de planta foi pequena, pois o que variou foi apenas a produção potencial de cada cultivar, sendo os demais fatores iguais.

O fator econômico fez a perda aceitável na produção diminuir, em média, 1,8\%. Considerando o nível de $5 \%$ como aceitável, a perda foi de 148,70, 166,31 e 166,74 $\mathrm{kg} \mathrm{ha}^{-1}$, e, ao utilizar o NT, o valor aceitável de perda foi reduzido para 107,06, 106,44 e 106,71 kg ha-1, para os cultivares Pérola, BRS Pontal e IPR Juriti, respectivamente. Com o quilo pago do feijão ao produtor de US\$ 0.92 na época da realização do ensaio, a perda média seria de $\mathrm{R} \$ 217,00$ (US\$ $98.19 \mathrm{ha}^{-1}$ ), superando o custo de uma nova aplicação em pós-emergência, orçada em R\$ 173,63 (US\$ 80.00). 
Considerando os NTs, os PAIs foram de 19, 16 e 3 DAE, para Pérola, BRS Pontal e IPR Juriti, respectivamente (Figura 4). O PAI foi reduzido em até no máximo quatro dias, quando comparado ao determinado considerando perda de 5\% como aceitável.

Ao se analisar o PADRE como ferramenta para estimar o PAI, as respectivas perdas percentuais diárias (PP) determinadas pela regressão linear (Figura 5) foram de 0,87, 0,95 e 0,85, para Pérola, BRS Pontal e IPR Juriti, respectivamente. Novamente, o cultivar IPR Juriti foi o mais sensivel à interferência, devido ao seu hábito de crescimento indeterminado tipo II. Esses valores (PP) são semelhantes aos obtidos por Parreira et al. (2012), que obtiveram valores de 0,83 e 0,85\%, em trabalhos realizados com a mesma metodologia e cultivar de crescimento indeterminado tipo III (cv. Rubi).

Tabela 5 - Períodos anteriores à interferência $(\mathrm{PAI})$ considerando as abordagens com $5 \%$ de redução na produtividade, utilizando o nível de tolerância (NT) calculado pelo PADRE, para os cultivares Pérola, BRS Pontal e IPR Juriti, e a diferença de dias entre estes

\begin{tabular}{|l|c|c|c|}
\hline \multicolumn{4}{|c|}{ PAI (Dias após a emergência) } \\
\hline \multirow{2}{*}{ Parâmetro } & \multicolumn{3}{|c|}{ Cultivar } \\
\cline { 2 - 4 } & Pérola & BRS Pontal & IPR Juriti \\
\hline $5 \%$ & 22 & 20 & 7 \\
\hline NT & 19 & 16 & 3 \\
\hline PADRE & 7 & 5 & 6 \\
\hline (5\% - NT) & 3 & 4 & 4 \\
\hline (5\% - PADRE) & 15 & 15 & 1 \\
\hline
\end{tabular}
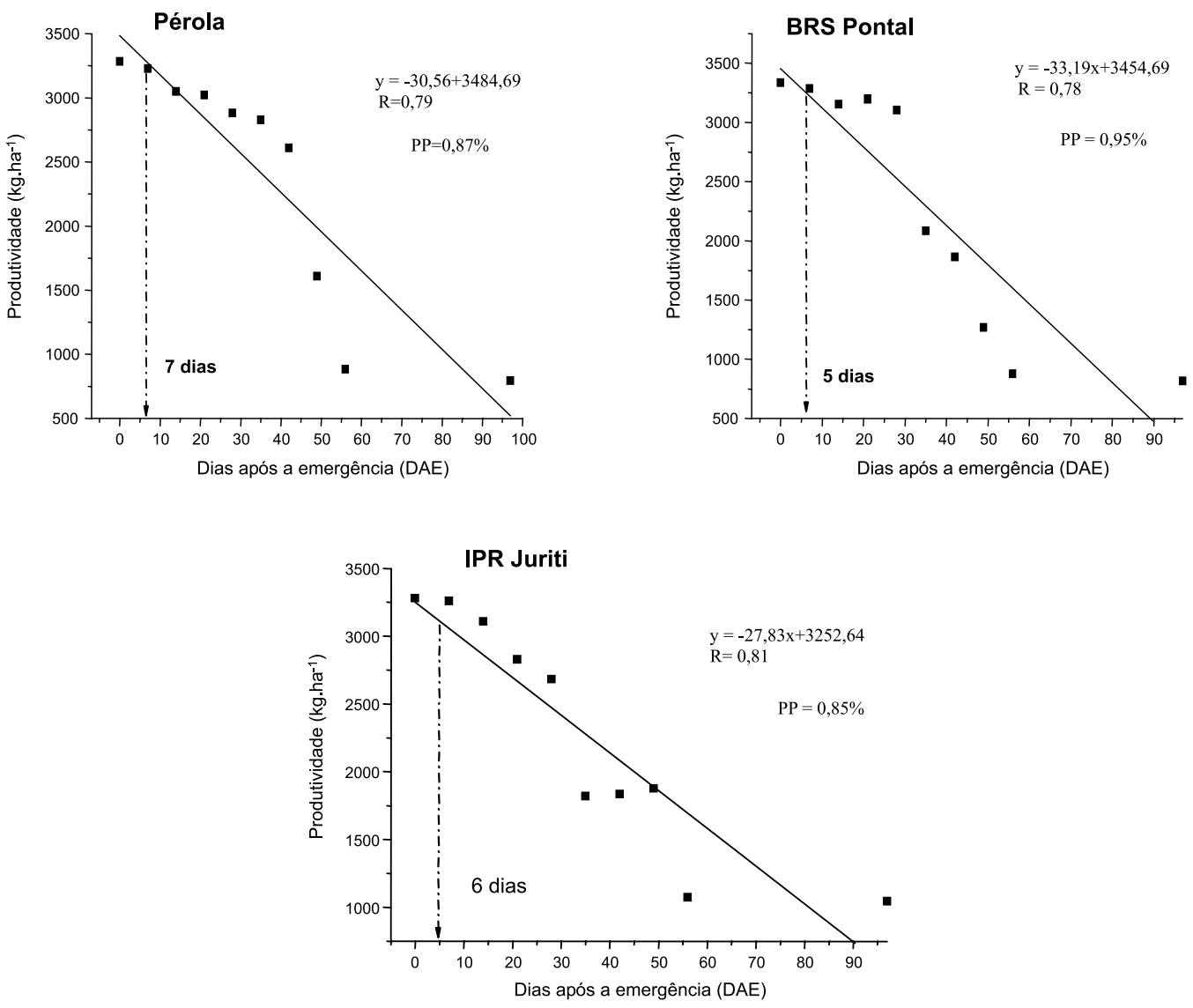

Regressões lineares do tipo $y=a+b x$, em que y representa o rendimento de grãos da cultura; $x$ representa o tempo de interferência; $a$ e $b$ são os parâmetros de ajuste; e R é o coeficiente de regressão. PP é o resultado da razão b/a e o Período indica a data máxima em que os valores são lineares, sendo utilizados na regressão linear.

Figura 5 - Período anterior ao dano no rendimento econômico (PADRE) da cultura do feijão ao final do período de convivência com as plantas daninhas, para os cultivares Pérola, BRS Pontal e IPR Juriti. 
Os PAIs utilizando o PADRE como estimativa foram de 7,5 e 6 DAE para Pérola, BRS Pontal e IPR Juriti, respectivamente (Figura 5), sendo extremamente baixos; a maioria não atingiu uma semana de convivência, resultando em redução de 15,15 e 1 dias, quando comparados com os obtidos no nível arbitrário de $5 \%$ de redução na produtividade (Tabela 5).

Se fosse adotado o nível de arbitrário de $5 \%$ na redução na produtividade, o máximo que se poderia perder na produção seria 148,70 , 166,31 e $166,74 \mathrm{~kg} \mathrm{ha}^{-1}$, para os cultivares Pérola, BRS Pontal e IPR Juriti, respectivamente. Contudo, se o PADRE fosse adotado, as perdas seriam bem menores, chegando a $113,78,104,12$ e $116,64 \mathrm{~kg} \mathrm{ha}^{-1}$, e em niveis econômicos a diferença seria de $\mathrm{R} \$ 69,70 \mathrm{ha}^{-1}$ (US\$ 32.12 ha $^{-1}$ ), R\$ 124,14 ha-1 (US\$ 57.21 ha $^{-1}$ ) e R\$ 100,01 ha h $^{-1}$, (US\$ 46.09 ha $^{-1}$ ); contudo, não chegaria ao valor de uma nova aplicação de herbicida em pós-emergência por hectare, que foi de R\$171,63 (US\$ 80.00).

O cultivar IPR Juriti foi o que obteve o menor PAI em todas as análises, principalmente utilizando o NT, em que o convívio de apenas três dias com a planta daninha já foi suficiente para ter queda significativa na produtividade, mostrando que características morfofisiológicas específicas do genótipo podem estar diretamente relacionadas à habilidade competitiva (Scursoni \& Satorre et al., 2005).

Os valores de PAI obtidos nas três formas analisadas foram muito baixos, em torno de $20 \mathrm{DAE}$, estando a planta próximo ao estádio V3 (com apenas duas folhas trifoliadas totalmente expandidas), sendo muito sensiveis à interferência, conforme relatado por Cobucci (1999).

Independentemente do modo de determinação do período anterior à interferência das plantas daninhas na cultura do feijão, o manejo delas deve ser feito. Sendo o controle químico, se o PAI encontrado, estipulado arbitrariamente em 5\% de redução na produtividade, ou calculado economicamente (NT ou PADRE), for muito no início da emergência da cultura (3 a $10 \mathrm{DAE}$ ), o que vai prevalecer na tomada de decisão é a característica do herbicida e não o nível econômico estabelecido nem características do genótipo utilizado, como, por exemplo, as características competitivas.

Para o produtor, determinar o PAI segundo critérios econômicos se mostrou mais vantajoso, mas com ressalvas, pois, dependendo da abordagem escolhida (PADRE), pode-se reduzir extremamente o PAI sem obter retorno econômico desejável. Contudo, o nível arbitrário de 5\% na perda de produtividade ainda se mostra prático para determinar o PAI, pois dispensa cálculos e sua diferença em relação ao NT (que se mostrou o melhor parâmetro) não foi maior que quatro dias.

Os períodos anteriores à interferência foram de 22, 20 e 7 dias de convivência no nível aceitável de 5\% de redução, de 19, 16 e 3 dias de convivência utilizando o NT e de 7,5 e 6 dias utilizando o PADRE, para os cultivares de feijão Pérola, BRS Pontal e IPR Juriti, respectivamente, que estavam convivendo com a comunidade infestante composta predominantemente pelas espécies $R$. raphanistrum, Digitaria sp., C. rotundus, X. strumarium e P. oleraceae.

\section{LITERATURA CITADA}

AMARO, P.; BAGGIOLONI, M. Introdução à proteç̧ão integrada. Lisboa: FAO/DGPPA, 1982. v. 1. 276 p.

BRESSANIN, F. N. et al. Influência da adubação nitrogenada sobre a interferência de plantas daninhas em feijoeiro.

R. Ceres, v. 60, n. 1, p. 43-52, 2013.

BORCHARTT, L. et al. Períodos de interferência de plantas daninhas na cultura do feijoeiro-comum (Phaseolus vulgaris L.) R. Ci. Agron., v. 42, n. 3, p. 725-734, 2011.

CANTO-DOROW, T. S.; LONGHI-WAGNER, H. M. Novidades taxonômicas em Digitaria Haller (Poaceae) e novas citações para o gênero no Brasil. INSULA, v. 30, n.1. p. 21-34, 2001.

CATON, B. P. et al. Weed shoot morphology effects on competitiveness for light in direct-seeded rice. Weed Res., v. 41, n. 2, p. 155-163, 2001.

CASPER, B. B.; JACKSON, B. R. Plant competition underground. Ann. Rev. Ecol. Syst., v. 28, n. 1, p. 545-570, 1997.

COBUCCI, T.; DI STEFANO, J. G.; KLUTHCOUSKI, J. Manejo de plantas daninhas na cultura do feijoeiro em plantio direto. Santo Antônio de Goiás: Embrapa Arroz e Feijão, 1999. 56 p. (Circular Técnica, 35). 
COMPANHIA NACIONAL DE ABASTECIMENTO CONAB. Preço pago ao produtor, conjuntura semanal: Feijão (Período 6 a 10 de agosto de 2012). Disponível em: $<$ http://www.conab.gov.br/OlalaCMS/uploads/arquivos/ 12_08_15_09_03_10_feijao06a10082012.pdf $>$. Acesso em: 15 ago. 2012.

DEUBER, R. Ciência das plantas daninhas: fundamentos. Jaboticabal: FUNEP, 1992. v. 1. 431 p.

\section{EMPRESA BRASILEIRA DE PESQUISA}

AGROPECUÁRIA - EMBRAPA. Catálogo de cultivares de feijão comum. Disponível em: $<$ http://

www.cnpaf.embrapa.br/feijao/htm>. Acesso em: 3 out. 2013.

FERREIRA, F. A. et al. Manejo de plantas daninhas. In: VIEIRA, C.; PAULA JR, T. Z. D.; BORÉM, A. (Org.) Feijão. Viçosa, MG: Universidade Federal de Viçosa, 2006. v. 2. p. 309-340.

FERREIRA, L. R.; FERREIRA, F. A.; SILVA, J. F. Manejo integrado de plantas daninhas na cultura do feijão de outonoinverno. Inf. Agropec., v. 17, n. 178, p. 353-358, 1994.

FONTES, J. R. A. et al. Manejo integrado de plantas daninhas. Planaltina: Embrapa-CPAC, 2003. 48 p. (Boletim Técnico, 103).

FREITAS, F. C. L. et al. Interferência de plantas daninhas na cultura do feijão-caupi. Planta Daninha, v. 27, n. 2, p. 241-247, 2009.

FRENDA A. S. The critical period of weed control in faba bean and chickpea in mediterranean areas. Weed Sci., v. 61, n. 3, p. 452-459, 2013.

GERLACH, G. A. X. et al. Análise econômica da produção de feijão em função de doses de nitrogênio e coberturas vegetais. Pesq. Agropec. Tropical., v. 43, n. 1, p. 42-43, 2013.

GHAMARI, H.; AHMADVAND, G. Weed interference affects dry bean yield and growth. Notulae Sci. Biol., v. 4, n. 3, p. 70-75, 2012.

KISSMANN, K. G.; GROTH, D. Plantas infestantes e nocivas. 2.ed. São Paulo: BASF, 1999. 978 p.

MODA-CIRINO, V. et al. IPR Juriti: common bean cultivar. Crop Breed. Appl. Biotechnol., v. 3, n. 4, p. 303-306, 2003.

MUELLER-DOMBOIS, D.; ELLEMBERG, H. Aims and methods of vegetation ecology. New York: John Willey \& Sons, 1974. 547 p.
OLIVEIRA, O. M. S. et al. Período de convivência das plantas daninhas com cultivares de feijão-caupi em várzea no Amazonas. Planta Daninha, v. 28, n. 3, p. 523-530, 2010 .

PARREIRA, M. C. et al. Interferencia de malezas en el cultivo de frijol en dos sistemas de labranzas.

Planta Daninha, v. 31, n. 2, p. 319-327, 2013.

PARREIRA, M. C. et. al. Modeling of weeds interference periods in bean. Planta Daninha, v. 30, n. 4, p. 713-720, 2012.

PITELLI, R. A. Interferência de plantas daninhas em culturas agrícolas. Inf. Agropec., v. 11, n. 129, p. 19-27, 1985.

PORTUGAL, J. Nível crítico de dano (NCD) de infestantes na cultura do tomate de indústria. In: VIDAL, R. A.; PORTUGAL, J.; SHORA NETO, F. Nível crítico de dano de infestantes em culturas anuais. Porto Alegre: Evangraf, 2010. p. 57-72.

RICHETTI, A.; MELLO, C. L. P. Análise da viabilidade econômica do cultivo do feijão-comum, safra 2013, em Mato Grosso do Sul. Dourados: Embrapa-CPAO, 2012. 10 p. (Embrapa Agropecuária Oeste, Comunicado Técnico, 183).

SANTOS, J. B.; GAVILANES, M. L. Botânica. In: VIEIRA, C.; PAULA JÚNIOR, T. J.; BORÉM, A. (Eds). Feijão. 2.ed. Viçosa, MG: Universidade Federal de Viçosa, 2006. p. 41-65.

SCHOLTEN, R.; PARREIRA, M. C.; ALVES, P. L. C. A. Período anterior à interferência das plantas daninhas para o cultivar de feijoeiro 'Rubi' em função do espaçamento e da densidade de semeadura. Acta Sci. Agron., v. 33, n. 2, p. 313-320, 2011.

SCURSONI, J. A.; SATORRE, E. H. Barley

(Hordeumvulgare) and wild oat (Avenafatua) competition is affected by crop and weed density. Weed Technol., v. 19, n. 4, p. 790-795, 2005.

TAVARES, C. J. et al. Fitossociologia de plantas daninhas na cultura do feijão. R. Bras. Ci. Agr., v. 8, n. 1, p. 27-32, 2013.

VIDAL, R. A.; FLECK, N. G.; MEROTTO JR., A. Período anterior ao dano no rendimento econômico (Padre): nova abordagem sobre os períodos de interferência entre plantas daninhas e cultivadas. Planta Daninha, v. 23, n. 3, p. $387-396,2005$ 